\title{
Functional characterization of human umbilical cord-derived mesenchymal stem cells for treatment of systolic heart failure
}

\author{
ZHIHUA FANG ${ }^{1,2}$, XIAOGUANG YIN ${ }^{2}$, JIANZHONG WANG ${ }^{1}$, NA TIAN ${ }^{2}$, QIANG AO $^{3}$, \\ YONGQUAN GU ${ }^{4}$ and YING LIU ${ }^{2,5}$ \\ ${ }^{1}$ Department of Hematology, Siping Hospital of China Medical University; ${ }^{2}$ Jilin Tuhua Bioengineering Company Limited, \\ Siping, Jilin 136000; ${ }^{3}$ Department of Tissue Engineering, China Medical University, Shenyang, Liaoning 110122; \\ ${ }^{4}$ Department of Vascular Surgery, Xuanwu Hospital, Capital Medical University, Beijing 100053; \\ ${ }^{5}$ The Key Tissue Engineering of Jilin Province, Siping, Jilin 136000, P.R. China
}

Received March 11, 2016; Accepted September 22, 2016

DOI: $10.3892 /$ etm.2016.3748

\begin{abstract}
Congestive heart failure (HF) is a leading cause of morbidity and mortality worldwide. Although advances in medical therapy, mechanical support and heart transplantation have been made, almost half of all patients with HF succumb to the disease within five years of the initial diagnosis. Therefore, treatment methods need to be identified to restore the structure and function of cardiac muscle. Three patients with HF caused by ischemic cardiomyopathy received human umbilical cord-derived mesenchymal stem cell (HUC-MSC) intravenous infusion were included in the present study. Two patients demonstrated a $65.1 \%$ increase in left ventricular ejection fraction (LVEF) at the end of 3 months, which was maintained increasing $47.8 \%$ at the end of 12 months post-HUC-MSC intravenous infusion. LVEF of patient 1 decreased slowly in the observation period. This LVEF improvement was associated with significant improvements in the clinical parameters of the New York Heart Association class, and six-minute walk test in the coupled time. The third patient showed significant improvement in the six-minute walk test at the end of 12 months, while the other parameters did not change obviously. There were no severe adverse events during and post-HUC-MSC transplantation. During follow-up, no other immunosuppressive drugs were used. In conclusion, HUC-MSC therapy is a reasonable salvage treatment in HF. Future large-scale randomized clinical trials are likely to be designed to elucidate the efficacy of the HUC-MSC transplantation therapy on HF.
\end{abstract}

Correspondence to: Professor Ying Liu, The Key Tissue Engineering of Jilin Province, 89 Nanyingbin Road, Siping, Jilin 136000, P.R. China

E-mail: 1y3641829@163.com

Key words: efficacy, heart failure, human umbilical cord-derived mesenchymal stem cells, intravenous infusion, safety

\section{Introduction}

Congestive heart failure (HF) is a leading cause of morbidity and mortality worldwide (1). Despite advances in medical therapy, mechanical support and heart transplantation, nearly half of all patients with HF succumb to the disease within five years of the initial diagnosis. Therefore, novel strategies need to be investigated to restore the structure and function of cardiac muscle.

Transplantation of mesenchymal stem cells (MSCs) is under evaluation as a regenerative therapeutic approach for HF $(2,3)$. In previous studies, MSCs showed marginal improvement of cardiac function in animals and humans with HF (4,5). In addition, MSCs have the potential for clinical benefit in cardiovascular disease based on their characteristics of anti-fibrotic, anti-inflammatory, and proangiogenic properties $(6,7)$, and their ability to stimulate endogenous progenitor cells (8). Moreover, MSCs can be isolated from bone marrow, umbilical cord (UC) blood, and connective tissue (Wharton's jelly) (9), and can be expanded in culture to use as a source of stem cells to elicit cardiac repair. In previous studies, we investigated the safety and efficacy of human UC-MSCs (HUC-MSCs) in rat (10-12) and human bone non-union (13).

In the present study, we describe our experience using HUC-MSCs to treat patients with HF. The effect of HUC-MSCs on the HF was then assessed in the following 12 months.

\section{Materials and methods}

Basic principles and ethical considerations. The protocol of the present study was approved by the Institutional Review Board and the Ethics Committee of Siping Hospital of China Medical University. The study was conducted in compliance with current Good Clinical Practice standards and in accordance with the principles set forth under the Declaration of Helsinki (1989).

Isolation and propagation of HUC-MSCs. The HUC-MSC doses used in this study were derived from two donated UCs obtained from healthy mothers during routine term elective caesarean section birth. Fully informed consent was obtained 
several weeks prior to delivery. HUC-MSC were isolated and propagated as previously described (10-13). UCs were filled with $0.1 \%$ collagenase (Sigma-Aldrich, St. Louis, MO, USA) in PBS and incubated at $37^{\circ} \mathrm{C}$ for $20 \mathrm{~min}$. Each UC was washed with proliferation medium [a-minimal essential medium (MEM), 10\% human AB serum; Gibco, Grand Island, NY, USA], and the detached cells were harvested after gentle massage of the UC. The cells were centrifuged at $300 \mathrm{x} g$ for $10 \mathrm{~min}$, resuspended in proliferation medium to seed in $75-\mathrm{cm}$ 2 flasks at the density of $5 \times 10^{7}$ cells $/ \mathrm{ml}$. After $24 \mathrm{~h}$ of incubation, non-adherent cells were removed and the culture medium was replaced every 3 days. The adherent cells were cultured until they reached $80-90 \%$ confluence.

Flow cytometry. Flow cytometry was performed to analyze the cell-surface expression of typical protein markers. The adherent cells were incubated with the following anti-human primary antibodies CD31-phycoerythrin (PE), CD45-fluorescein isothiocyanate (FITC), CD90-R-PE, HLA-DR-R-PE (Becton-Dickinson, Franklin Lakes, NJ, USA). The total of 10,000 labeled cells were analyzed using a Guava easyCyte flow cytometer running Guava Express Plus software (Guava Technologies, Inc., Hayward, CA, USA).

Patients. The inclusion criteria were stable symptomatic patients of ischemic cardiomyopathy [New York Heart Association (NYHA) functional class II/III], older than 18 years, left ventricular ejection fraction (LVEF) $<40 \%$. The exclusion criteria were non-cardiac serious diseases expected to reduce the patients's short-time survival, recent ( $<6$ months) myocardial infarction or an implanted pacemaker. The patients provided written informed consent stating agreement to the treatment according to the Siping Hospital of China Medical University. The general characteristics of the patients are shown in Table I.

HUC-MSC intravenous infusion. HUC-MSCs (10 ml) with a cell density of $5 \times 10^{6}-1 \times 10^{7} / \mathrm{ml}$ was given intravenously at a rate of no more than $12.5 \times 10^{6} / \mathrm{min}$ and flushed with $20 \mathrm{ml}$ saline to ensure full cell dose delivery. Once the needle was fully withdrawn, the puncture site was wrapped with sterilized dressing. The patients remained in the supine decubitus on the operation bed for another $30 \mathrm{~min}$ before off-bed activities. The patient was monitored [temperature, blood pressure, pulse and electrocardiograph (ECG)] at 0, 15, 30, 45 and $60 \mathrm{~min}$, and then hourly for a minimum of $4 \mathrm{~h}$.

Six-minute walk test. Patients underwent exercise testing using six-minute walk test a modified Bruce treadmill test. The patients were monitored throughout with tests being terminated by physiological markers (ST changes, arrhythmias, or chest pain) or by patient request.

Clinical, functional assessment and definitions. i) Primary safety assessments included monitoring and recording of all adverse and serious adverse events. All patient were monitored (temperature, blood pressure, pulse and oxygen saturation) at $15,30,45$ and $60 \mathrm{~min}$, and then hourly for a minimum of $4 \mathrm{~h}$. They were discharged 24-h post-transplantation given that the patient was afebrile and hemodynamically stable with no
Table I. Baseline characteristics of the study population.

\begin{tabular}{|c|c|c|c|}
\hline \multirow[b]{2}{*}{ Variables } & \multicolumn{3}{|c|}{ Patient no. } \\
\hline & 1 & 2 & 3 \\
\hline Age (years) & 65 & 37 & 53 \\
\hline Gender (M/F) & $\mathrm{F}$ & M & M \\
\hline $\mathrm{BMI}\left(\mathrm{kg} / \mathrm{m}^{2}\right)$ & 23.62 & 27.39 & 27.85 \\
\hline $\begin{array}{l}\text { Duration of disease } \\
\text { (months) }\end{array}$ & 3 & 6 & 12 \\
\hline Hypertension & Yes & No & No \\
\hline Active smoker & Yes & No & No \\
\hline Diabetes mellitus & Yes & No & No \\
\hline $\begin{array}{l}\text { Family history of } \\
\text { any heart disease }\end{array}$ & No & No & No \\
\hline Hypercholesterolaemia & Yes & No & No \\
\hline \multicolumn{4}{|l|}{ Medical therapy } \\
\hline ACEI/ARB & Enalapril & Irbesartan & Enalapril \\
\hline$\beta$-blockers & Metoprolol & Bisoprolol & \\
\hline Diuretics & Furosemide & Furosemide & \\
\hline $\begin{array}{l}\text { Aldosterone } \\
\text { antagonists }\end{array}$ & Spironolactone & Spironolactone & \\
\hline Digoxin & Digoxin & & \\
\hline
\end{tabular}

BMI, body mass index; ACEI, angiotensin-converting enzyme inhibitor; $\mathrm{ARB}$, angiotensin receptor blocker.

signs of infection or any type of allergic reaction. Mortality and major adverse cardiovascular events (MACE) defined as all-cause death, myocardial infarction, hospitalization for $\mathrm{HF}$, or major arrhythmias were assessed at 3 months and 1 year.

ii) As exploratory secondary endpoints we investigated the efficacy of HUC-MSC infusion as follows: The change in global LVEF at 3, 6 and 12 months compared with baseline as assessed by advanced cardiac imaging and changes in left ventricular (LV) volumes; exercise capacity (six-minute walk test), and NYHA classification at 3,6 and 12 months compared with baseline.

Pharmacological therapy protocol. The patient's pharmacological therapy consisted of: i) Digoxin, $0.125 \mathrm{mg}$, once daily, p.o.; ii) $\beta$-acceptor blockers: Metoprolol, $6.25 \mathrm{mg}$, twice daily, p.o., or bisoprolol $2.5 \mathrm{mg}$ once daily, p.o.; iii) diuretic: Furosemide, $20 \mathrm{mg}$ once daily, i.v.; and/or spironolactone: $20 \mathrm{mg}$ once daily, p.o.; and iv) angiotensin-converting enzyme inhibitors: Enalapril, $5 \mathrm{mg}$ orally twice daily; irbesartan: $150 \mathrm{mg}$ orally once daily.

Statistical analysis. Statistical analysis was performed using SPSS 16.0 software (Chicago, IL, USA). Safety and exploratory efficacy secondary endpoints were observed for each patient against the baseline values. $\mathrm{P}<0.05$ was considered to indicate a statistically significant difference.

\section{Results}

Evaluation of HUC-MSCs. The cells derived from UC were observed $24 \mathrm{~h}$ after seeding (Fig. 1A), when part of the round 

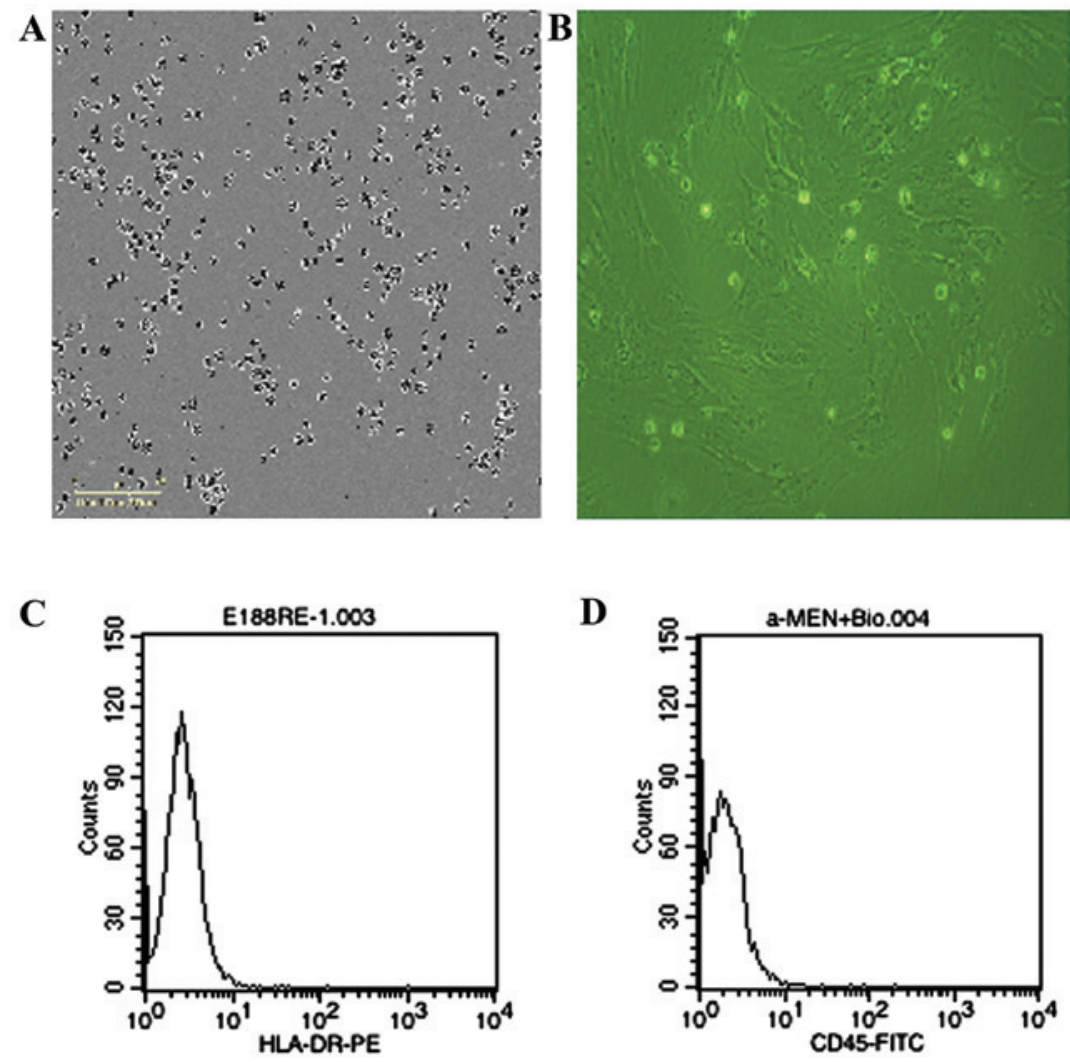

D

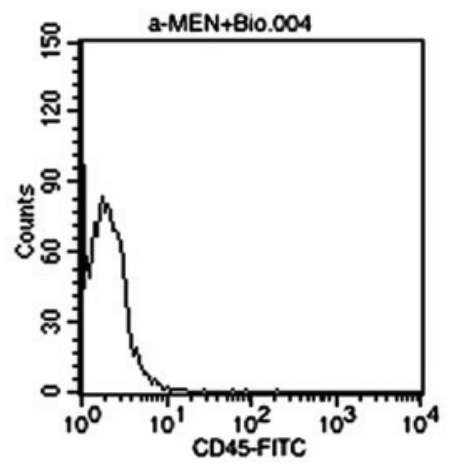

E
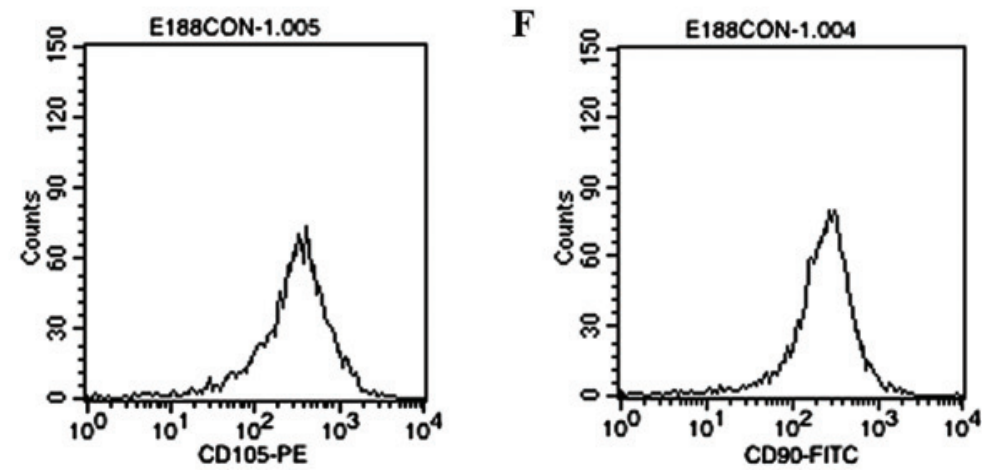

Figure 1. Characteristics of HUC-MSCs. (A) The cells derived from UC were observed at $24 \mathrm{~h}$ after they were seeded. (B) Fifth passage cells show typical fibroblast-shaped morphology. Fifth passage cells were analyzed for (C) HLA-DR, (D) CD45, (E) CD105, and (F) CD90 by flow cytometry. HUC-MSCs, human umbilical cord-derived mesenchymal stem cells; UC, umbilical cord.

mononuclear cells was adherent. Three days after inoculation, small colonies of the adherent cells with typical fibroblastshaped morphology were obtained (Fig. 1B). These primary cells reached monolayer confluence, after planting for 5-6 days, when passaged for the first time. The fifth passage cells were analyzed by flow cytometry, and were strongly positive for CD105 and CD90, but negative for CD45 and HLA-DR (Fig. 1C-F).

General characteristics of the HF patients. The general characteristics of the patients are shown in Table I. The patients included 2 males and 1 female with a mean age of 51.7 years (range, 37-65 years) at HUC-MSCs infusion. The patients were enrolled between January 2010 and January 2012. The etiology of the HF was ischemic cardiomyopathy. All the patients reached the 3, 6 and 12 months primary endpoint (Table I).
LVEF. Two patients demonstrated a $65.1 \%$ increase in LVEF at the end of 3 months, which was maintained increasing to $47.8 \%$ at the end of 12 months post-HUC-MSC intravenous infusion. LVEF of patient 1 decreased slowly in the observation period (Table II).

Exercise capacity. All the patients underwent a six-minute walk test at baseline, 3, 6 and 12 months. Patient 1 got a transient decrease at the end of 3 months, patient 2 got a transient increase at the end of 3 months, and then decreased slowly. After 12 months, there was significant improvement in six-minute walk test in two patients post-transplantation (Table II).

NYHA. Each patient who showed improvement in the NYHA classification improved within 3 months of post-transplantation. 
Table II. LVEF and cardiac dimensions.

\begin{tabular}{|c|c|c|c|}
\hline \multirow[b]{2}{*}{ Variables } & \multicolumn{3}{|c|}{ Patient no. } \\
\hline & 1 & 2 & 3 \\
\hline \multicolumn{4}{|l|}{ Primary endpoint (LVEF) } \\
\hline Baseline (\%) & 39.1 & 20.3 & 31.6 \\
\hline Post-transplantation 3 months (\%) & 29.9 & 60.1 & 52.2 \\
\hline Post-transplantation 6 months (\%) & 25.3 & 57.6 & 52.6 \\
\hline Post-transplantation 12 months (\%) & 23.1 & 56.3 & 46.7 \\
\hline \multicolumn{4}{|l|}{ Secondary endpoint } \\
\hline \multicolumn{4}{|l|}{ LVEDV } \\
\hline Baseline (mls) & 90.2 & 98 & 78.2 \\
\hline Post-transplantation 3 months & 145.1 & 110 & 79.6 \\
\hline Post-transplantation 6 months & 106.5 & 115 & 69.1 \\
\hline Post-transplantation 12 months & 164.4 & 203 & 98.5 \\
\hline \multicolumn{4}{|l|}{ LVESV } \\
\hline Baseline (mls) & 55.6 & 78 & 54.4 \\
\hline Post-transplantation 3 months & 103.4 & 44 & 38.2 \\
\hline Post-transplantation 6 months & 76.1 & 80 & 33.1 \\
\hline Post-transplantation 12 months & 134.1 & 88 & 53.5 \\
\hline \multicolumn{4}{|l|}{ Six-minute walk test } \\
\hline Baseline (ml) & 211.5 & 460.5 & 310.2 \\
\hline Post-transplantation 3 months (ml) & 196.5 & 462 & 365.3 \\
\hline Post-transplantation 6 months (ml) & 267.0 & 457.5 & 347.5 \\
\hline Post-transplantation 12 months (ml) & 245.6 & 447 & 332.5 \\
\hline \multicolumn{4}{|l|}{ NYHA functional class } \\
\hline Baseline & III & III & II \\
\hline Post-transplantation 3 months & III & III & II \\
\hline Post-transplantation 6 months & II & II & I \\
\hline Post-transplantation 12 months & II & I & I \\
\hline
\end{tabular}

LVEF, left ventricular ejection fraction; LVEDV, left ventricular end-diastolic volume; LVESV, left ventricular end-systolic volume; NYHA, New York Heart Association.

After 12 months, this pattern continued with the three (100\%) patients improving (Table II).

Safety. There were no complications or adverse events associated with HUC-MSC transplantation. No cases of distal coronary artery occlusion, acute cardiac dysfunction, and ventricular arrhythmia occurred.

\section{Discussion}

In the present study, we reported the safety and efficacy of HUC-MSCs in the treatment of HF caused by ischemic cardiomyopathy in the 12 month follow-up duration. Two patients demonstrated a $65.1 \%$ increase in LVEF at the end of 3 months, which was maintained increasing to $47.8 \%$ at the end of 12 months post-HUC-MSC intravenous infusion. Our data provided significant evidence for the short-term safety of the cell therapy approach in at least moderate HF, and provided novel insights into the improvement of cardiac function.
NYHA class improvement was observed in all the patients, while LVEF improvement was observed in two patients at the end of the 12 month post-HUC-MSC transplantation. Thus, our data indicate that HUC-MSC intravenous infusion was beneficial. In the present study, we did not observe any improvement in intermediate and clinical endpoints. Similar beneficial effects on cardiac function with BMC therapy have been shown in other early phase studies with the most recent demonstrating improvements to 5 years post-cell therapy $(14,15)$. Thus, HUC-MSC transplantation attenuation of the HF process was related to cardiac regeneration.

The pathophysiology of HF and the related syndrome is complex, and many factors contribute to diastolic dysfunction, including vascular and myocardial stiffening (1). Generalized stiffening that occurs throughout the cardiovascular system, and LV diastolic dysfunction may be associated with changes in intrinsic myocyte stiffness. In previous studies, we investigated the safety and efficacy of HUC-MSCs in rat liver fibrosis (13), a fibrosic score that was reduced 8 weeks post-translation. Thus, our data suggest HUC-MSCs used in the present study are capable of attenuating cardiac fibrosis process. The results shown herein supported the hypothesis that the beneficial effects of HUC-MSC transplantation in part mediated by antifibrotics.

There are several limitations of the present study. The HF patients received allogeneic HUC-MSCs; thus, we could not investigate the effect of autologous MSCs in this specific HF population. Furthermore, the patients with HF received the same number of cells, and no control group/patients were included in the present study. Despite these limitations, our data provided novel insights into the positive cardiac function effect of HUC-MSC transplantation in patients with HF. Rigorous study design involving appropriate control arms are required, as previously suggested (16).

In conclusion, the study has demonstrated a potent and clinically relevant efficacy outcome of HUC-MSC transplantation to treat patients with advanced $\mathrm{HF}$, and the procedure is safe and associated with improvement in LVEF 3 months after therapy, which is maintained at 12 months. Our data supported a potential clinical benefit of this therapy. Future large-scale randomized clinical trials are likely to be designed to elucidate the efficacy of HUC-MSC transplantation therapy on HF.

\section{References}

1. Senni M, Paulus WJ, Gavazzi A, Fraser AG, Díez J, Solomon SD, Smiseth OA, Guazzi M, Lam CS, Maggioni AP, et al: New strategies for heart failure with preserved ejection fraction: the importance of targeted therapies for heart failure phenotypes. Eur Heart J 35: 2797-2815, 2014.

2. Hare JM, Fishman JE, Gerstenblith G, DiFede Velazquez DL, Zambrano JP, Suncion VY, Tracy M, Ghersin E, Johnston PV, Brinker JA, et al: Comparison of allogeneic vs autologous bone marrow-derived mesenchymal stem cells delivered by transendocardial injection in patients with ischemic cardiomyopathy: the POSEIDON randomized trial. JAMA 308: 2369-2379, 2012.

3. Heldman AW, DiFede DL, Fishman JE, Zambrano JP, Trachtenberg BH, Karantalis V, Mushtaq M, Williams AR, Suncion VY, McNiece IK, et al: Transendocardial mesenchymal stem cells and mononuclear bone marrow cells for ischemic cardiomyopathy: the TAC-HFT randomized trial. JAMA 311: $62-73,2014$. 
4. Perin EC, Willerson JT, Pepine CJ, Henry TD, Ellis SG, Zhao DX, Silva GV, Lai D, Thomas JD, Kronenberg MW, et al; Cardiovascular Cell Therapy Research Network (CCTRN): Effect of transendocardial delivery of autologous bone marrow mononuclear cells on functional capacity, left ventricular function, and perfusion in chronic heart failure: the FOCUS-CCTRN trial. JAMA 307: 1717-1726, 2012.

5. Mathiasen AB, Jørgensen E, Qayyum AA, Haack-Sørensen M, Ekblond $\mathrm{A}$ and Kastrup $\mathrm{J}$ : Rationale and design of the first randomized, double-blind, placebo-controlled trial of intramyocardial injection of autologous bone-marrow derived mesenchymal stromal cells in chronic ischemic heart failure (MSC-HF Trial). Am Heart J 164: 285-291, 2012.

6. Williams AR and Hare JM: Mesenchymal stem cells: biology, pathophysiology, translational findings, and therapeutic implications for cardiac disease. Circ Res 109: 923-940, 2011.

7. Cao Y, Gomes SA, Rangel EB, Paulino EC, Fonseca TL, Li J, Teixeira MB, Gouveia CH, Bianco AC, Kapiloff MS, et al: $S$-nitrosoglutathione reductase-dependent PPAR $\gamma$ denitrosylation participates in MSC-derived adipogenesis and osteogenesis. J Clin Invest 125: 1679-1691, 2015.

8. Premer C, Blum A, Bellio MA, Schulman IH, Hurwitz BE, Parker M, Dermarkarian CR, DiFede DL, Balkan W, Khan A, et al: Allogeneic mesenchymal stem cells restore endothelial function in heart failure by stimulating endothelial progenitor cells. EBioMedicine 2: 467-475, 2015.

9. Castro-Manrreza ME, Mayani H, Monroy-García A Flores-Figueroa E, Chávez-Rueda K, Legorreta-Haquet V, Santiago-Osorio E and Montesinos JJ: Human mesenchymal stromal cells from adult and neonatal sources: a comparative in vitro analysis of their immunosuppressive properties against $\mathrm{T}$ cells. Stem Cells Dev 23: 1217-1232, 2014.
10. Qu Z, Guo S, Fang G, Cui Z and Liu Y: AKT pathway affects bone regeneration in nonunion treated with umbilical cord-derived mesenchymal stem cells. Cell Biochem Biophys 71: 1542-1551, 2014.

11. Qu Z, Guo L, Fang G, Cui Z, Guo S and Liu Y: Biological characteristics and effect of human umbilical cord mesenchymal stem cells (hUC-MSCs) grafting with blood plasma on bone regeneration in rats. Cell Biochem Biophys 63: 171-181, 2012.

12. Liu Y, Shi ZL and Zhao Z: Transplantation of human umbilical cord-derived mesenchymal stem cells improves hepatic fibrosis in rats with carbon etrachloride-induced hepatic cirrhosis. Chinese J Tissue Engineering Res 16: 1837-1840, 2012 (In Chinese).

13. Qu Z, Fang G, Cui Z and Liu Y: Cell therapy for bone nonunion: a retrospective study. Minerva Med 106: 315-321, 2015.

14. Seth S, Bhargava B, Narang R, Ray R, Mohanty S, Gulati G, Kumar L, Airan B and Venugopal P; AIIMS Stem Cell Study Group: The ABCD (autologous bone marrow cells in dilated cardiomyopathy) trial a long-term follow-up study. J Am Coll Cardiol 55: 1643-1644, 2010.

15. Fischer-Rasokat U, Assmus B, Seeger FH, Honold J, Leistner D, Fichtlscherer S, Schächinger V, Tonn T, Martin H, Dimmeler S, et al: A pilot trial to assess potential effects of selective intracoronary bone marrow-derived progenitor cell infusion in patients with nonischemic dilated cardiomyopathy: final 1-year results of the transplantation of progenitor cells and functional regeneration enhancement pilot trial in patients with nonischemic dilated cardiomyopathy. Circ Heart Fail 2: 417-423, 2009.

16. Gho JM, Kummeling GJ, Koudstaal S, Jansen Of Lorkeers SJ, Doevendans PA, Asselbergs FW and Chamuleau SA: Cell therapy, a novel remedy for dilated cardiomyopathy? A systematic review. J Card Fail 19: 494-502, 2013. 